\title{
A Multiple Resonant Frequencies Circular Reconfigurable Antenna Investigated with Wireless Powering in a Concrete Block
}

\author{
Shishir Shanker Punjala, ${ }^{1}$ Niki Pissinou, ${ }^{2}$ and Kia Makki ${ }^{3}$ \\ ${ }^{1}$ Tata Consultancy Services, Deccan Park, Madapur, Hyderabad 500081, India \\ ${ }^{2}$ School of Computing and Information Sciences, Florida International University, Miami, FL 33199, USA \\ ${ }^{3}$ School of Engineering and Technology, Miami Dade College, Wolfson Campus, Miami, FL 33132, USA \\ Correspondence should be addressed to Shishir Shanker Punjala; shesmesh9@gmail.com
}

Received 4 January 2015; Revised 17 April 2015; Accepted 29 April 2015

Academic Editor: Luis Landesa

Copyright (C) 2015 Shishir Shanker Punjala et al. This is an open access article distributed under the Creative Commons Attribution License, which permits unrestricted use, distribution, and reproduction in any medium, provided the original work is properly cited.

\begin{abstract}
A novel broadband reconfigurable antenna design that can cover different frequency bands is presented. This antenna has multiple resonant frequencies. The reflection coefficient graphs for this antenna are presented in this paper. The new proposed design was investigated along with RF MEMS switches and the results are also presented. Investigations were carried out to check the efficiency of the antenna in the wireless powering domain. The antenna was placed in a concrete block and its result comparison to that of a dipole antenna is also presented in this paper.
\end{abstract}

\section{Introduction}

Reconfigurable antennas [1] are preferred in modern wireless communication systems as they provide a single antenna that can be used for multiple application systems. By using switches, the basic characteristics of a reconfigurable antenna such as the operating frequency, bandwidth, polarization, and the radiation pattern can be tuned to a specific application. These basic characteristics are changed by increasing or decreasing the electrical length of the antenna. A frequency reconfigurable antenna [2] also has low isolation problems.

A novel Circular Reconfigurable Antenna is presented in this paper. Its reflection coefficient, radiation pattern, and gain results are also presented in this paper. The application of this antenna is extended to the wireless powering domain. Investigations were carried out placing the Circular Reconfigurable Antenna and a dipole antenna inside a concrete block. In separate instances, a dipole antenna and another Circular Reconfigurable Antenna were placed above the concrete block and the currents on the surface of the antennas were measured. All results presented in this paper were obtained using HFSS.

\section{CRA}

The Circular Reconfigurable Antenna (CRA) shown in Figure 1 contains a circular patch of radius $18.6 \mathrm{~mm}$ at the center. Three concentric circular rings are placed around the circular patch. Each concentric circular ring is connected to the next circular ring through four more switches. The concentric circular rings have a radius of $13 \mathrm{~mm}$ at a distance of $1 \mathrm{~mm}$ around it. This antenna was placed as shown in Figure 1 on top of a substrate of dimensions $148.8 \mathrm{~mm} \times 148.8 \mathrm{~mm}$ and thickness $1.5748 \mathrm{~mm}$.

The design equations [3] of a Circular Patch Antenna are given below:

$$
a=\frac{F}{\left\{1+\left(2 h / \pi \epsilon_{r} F\right)[\ln (\pi F / 2 h)+1.7726]\right\}^{1 / 2}},
$$

where

$$
F=\frac{8.791 \times 10^{9}}{f_{r} \sqrt{\epsilon_{r}}},
$$

$a$ is the radius of the Circular Patch Antenna. 


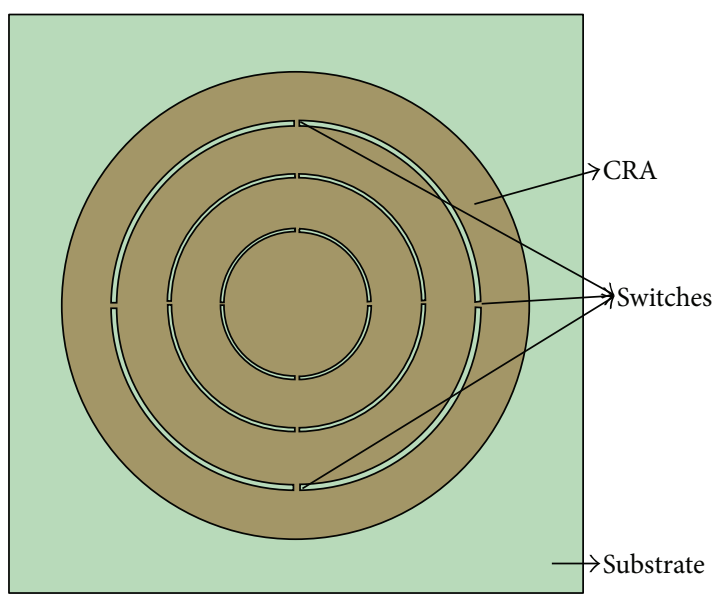

Figure 1: The Circular Reconfigurable Antenna (CRA).

The CRA was designed with the idea that if the radius of the antenna could be increased using switches then the resonating frequency of the antenna could also change. The CRA has four iterations. In the first iteration, only the circular patch is radiating and all the switches are open. In the second iteration, the first set of four switches are on. Thus, the first concentric circular ring and the circular patch are radiating. In the third and the fourth iterations, the third and the fourth set of switches are on. Thus, the third and the fourth concentric circular rings are also radiating. Using the above design equations, the central circular patch can be designed for any frequency band $(\mathrm{MHz}, \mathrm{GHz}$, or $\mathrm{THz})$ and the concentric rings can be used to vary the frequency of resonance.

\section{CRA with RF MEMS Switches}

In [4], the three-dimensional geometry of shunt capacitive RF MEMS switches was analyzed performing a full wave analysis. The CRA was analyzed in the fourth iteration by using the equivalent lumped circuit [4] model shown in Figure 2 for different geometries. A switch of dimensions [4] $280 \mu \mathrm{m} \times$ $120 \mu \mathrm{m}$ is used along with the CRA as shown in Figure 3. The equivalent circuit values [4] are inductance of $5.03 \mathrm{pH}$, capacitance of $9.31 \mathrm{pF}$, and resistance of $0.034 \mathrm{ohm}$ in the $\mathrm{ON}$ state.

\section{Concrete}

The permittivity of a concrete block $[1,5]$ shown in Figure 4 has been modeled assuming that it is lossy dielectric and that a slab has a real part and an imaginary part. The permittivity of a concrete block shown in Figure 4 can be written as

$$
\widehat{\varepsilon}=\varepsilon^{\prime}-\varepsilon^{\prime \prime},
$$

where $\varepsilon^{\prime}$ is the real part of complex permittivity of a concrete block and $\varepsilon^{\prime \prime}$ is the imaginary part of permittivity of a concrete block. By modeling a concrete block as a Debye

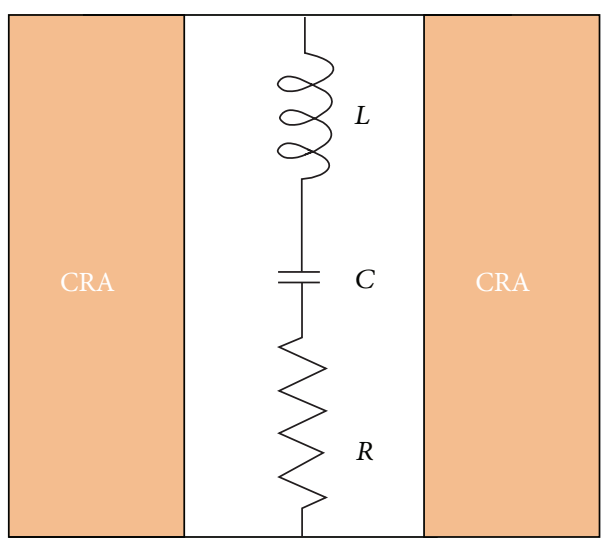

FIgURE 2: Equivalent circuit model of the capacitive RF MEMS switches [7].

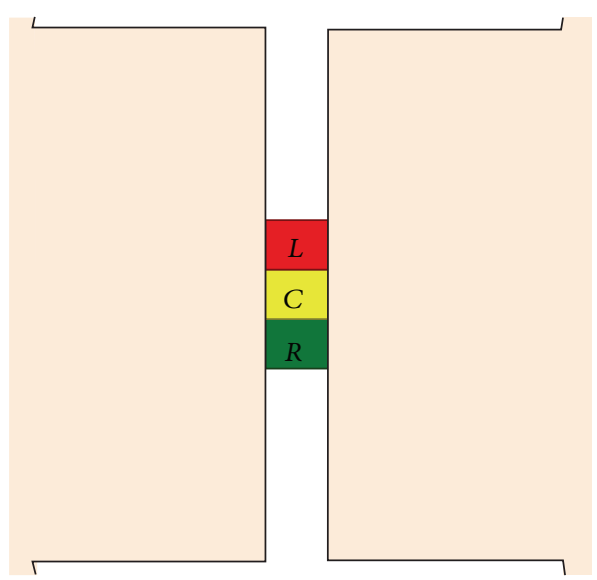

FIgURE 3: RF MEMS switches in the layout of the antenna.

material [1, 5], its frequency dependent complex relative permittivity obeys the following equation:

$$
\widehat{\varepsilon}(\omega)=\varepsilon^{\prime}(\omega)-\varepsilon^{\prime \prime}(\omega) .
$$

The concrete model used in these investigations contains a moisture content of $12 \%$. A CRA antenna and a dipole were placed inside a concrete block and the surface of the concrete block was excited using another CRA antenna and a dipole antenna.

\section{Current Consumption of Typical Sensors}

A temperature sensor $[1,6]$ consumes $300 \mu \mathrm{A}(\mu=$ Micro $=10^{-6}$ ) for $50 \mu \mathrm{Sec}$ for a stable reading every five seconds, and a humidity sensor consumes $2.8 \mathrm{~mA}$ for $150 \mathrm{msec}$ for a stable reading every thirty seconds. The radio frequency energy incident on the receiving antenna has to be converted to electrical energy [6] to enable wireless powering. 


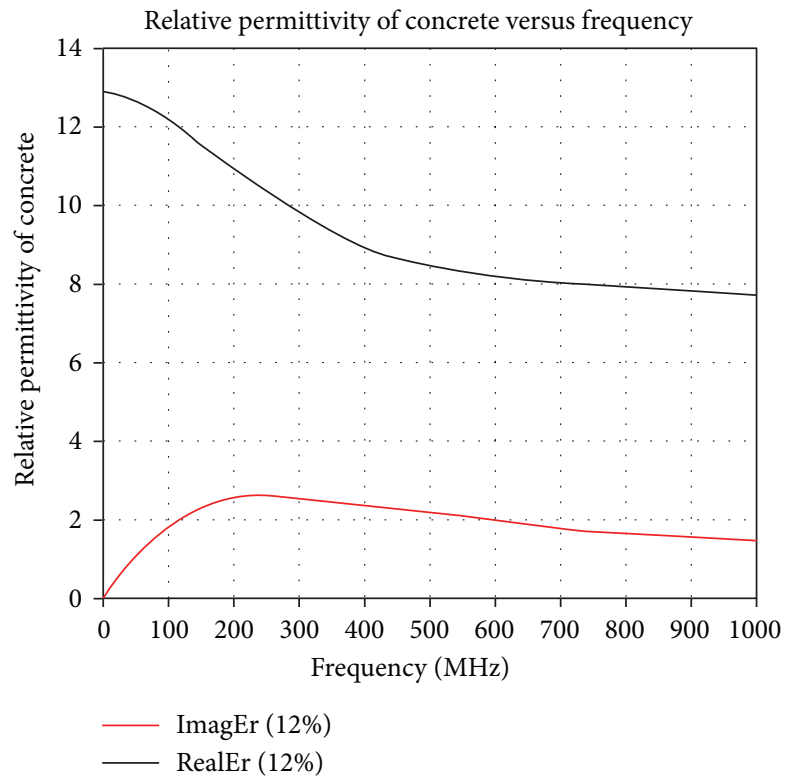

FIGURE 4: Relative permittivity of concrete for $12 \%$ moisture content $[1,5]$.

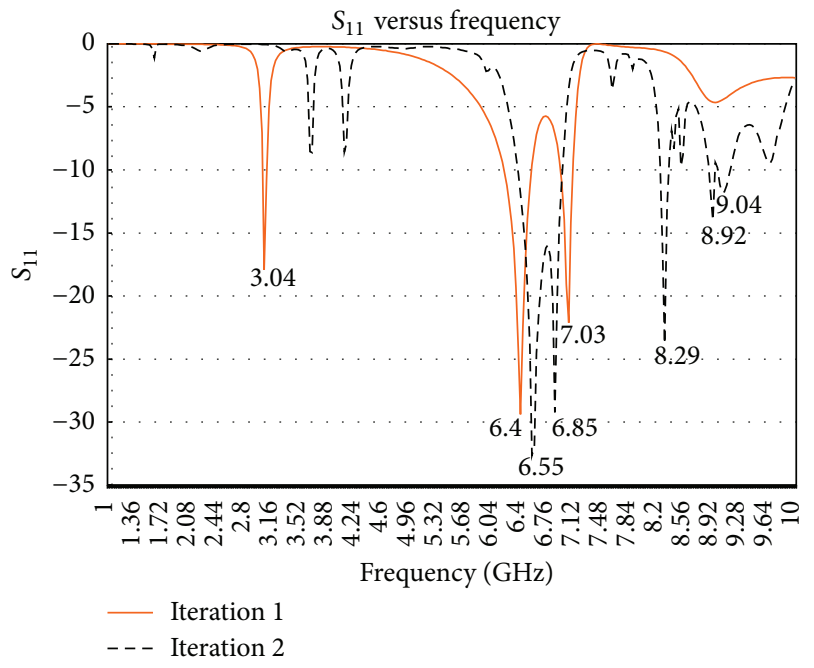

Figure 5: $S_{11}$ versus frequency $(\mathrm{GHz})$.

\section{CRA Results}

While simulating the CRA, open circuit was used when the switches were off and the patches were shorted when the switches were on. Figures 5 and 6 show the input reflection coefficient $S_{11}$ for the CRA iterations 1, 2, 3, and 4. The VSWR plots for the CRA iterations 1-4 are shown in Figures 7, 8, 9 , and 10 . The VSWR values for certain frequencies are very high, so the maximum value of 10 was chosen on the $y$ axis. This is the reason the VSWR values which are more than 10 are not visible in Figures 7, 8, 9, and 10. The antenna has a number of resonating frequencies from 3 to $9.5 \mathrm{GHz}$. The resonating frequency is given at every peak in the input
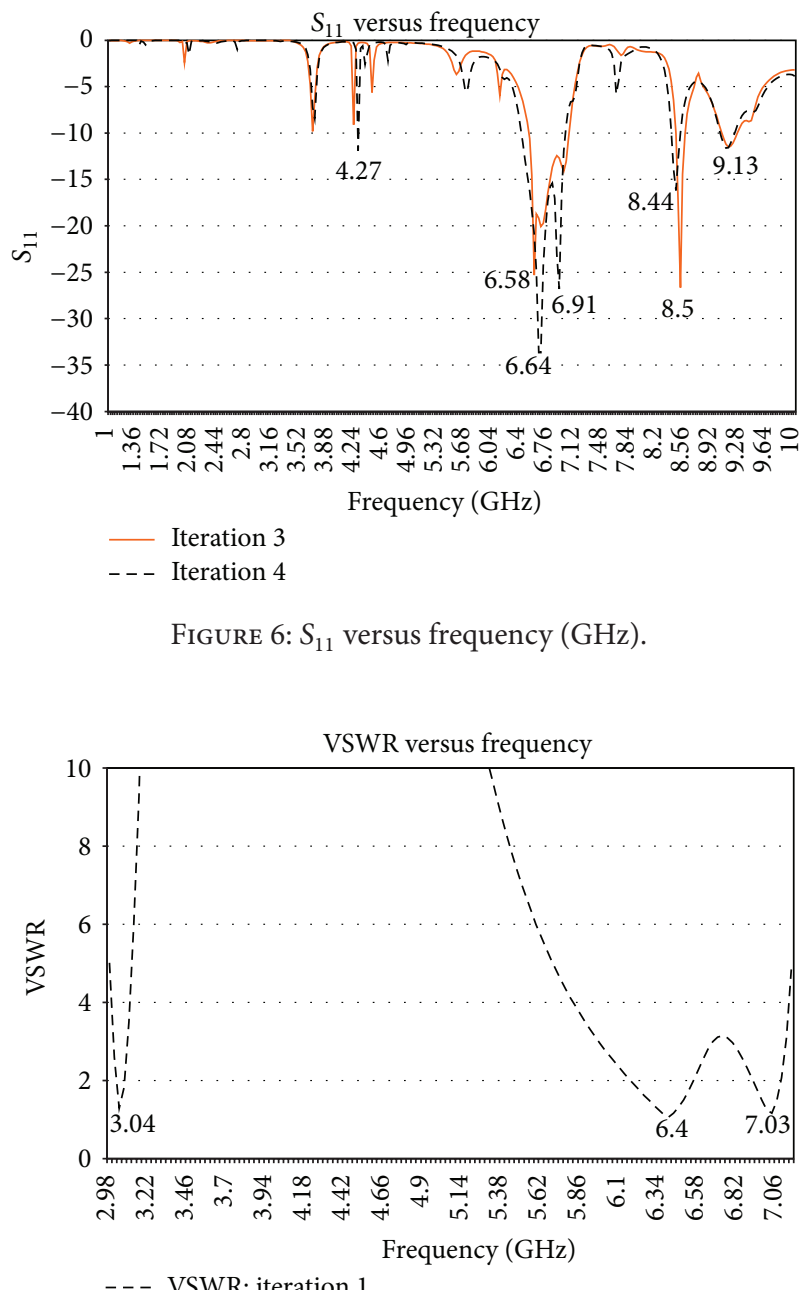

FIGURE 7: VSWR for iteration 1. 


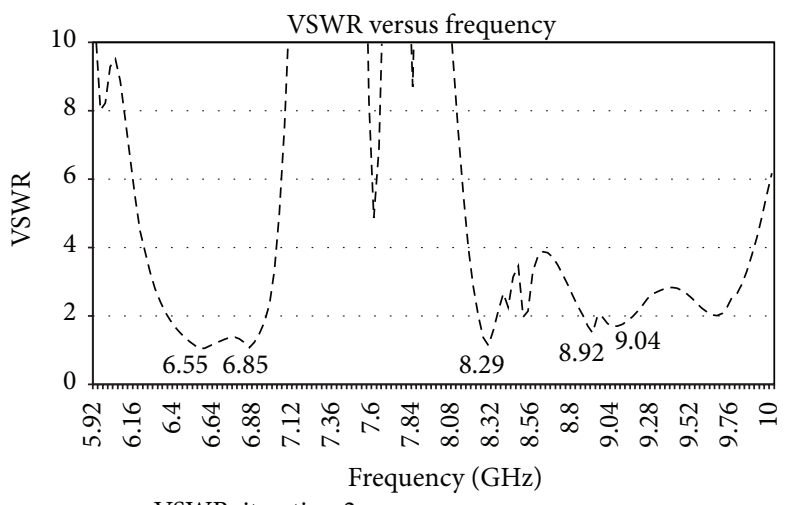

FIGURE 8: VSWR for iteration 2.

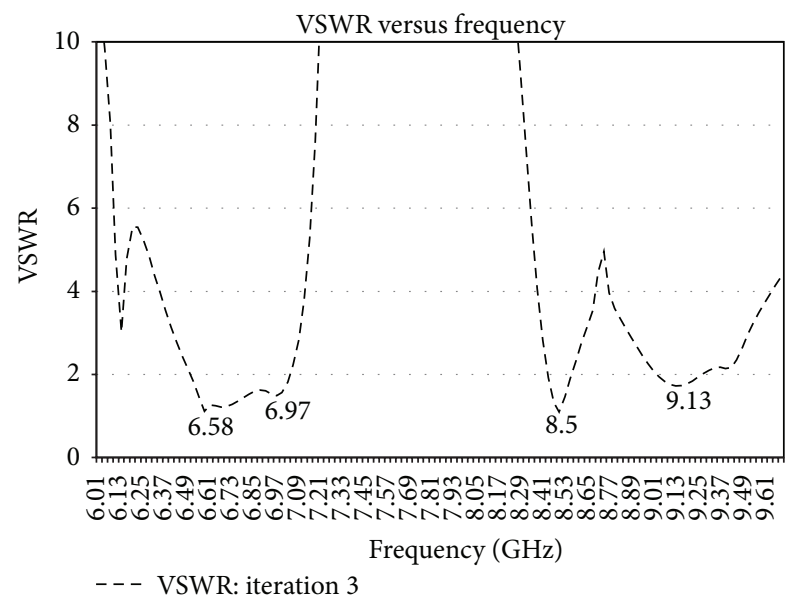

FIgURE 9: VSWR for iteration 3.

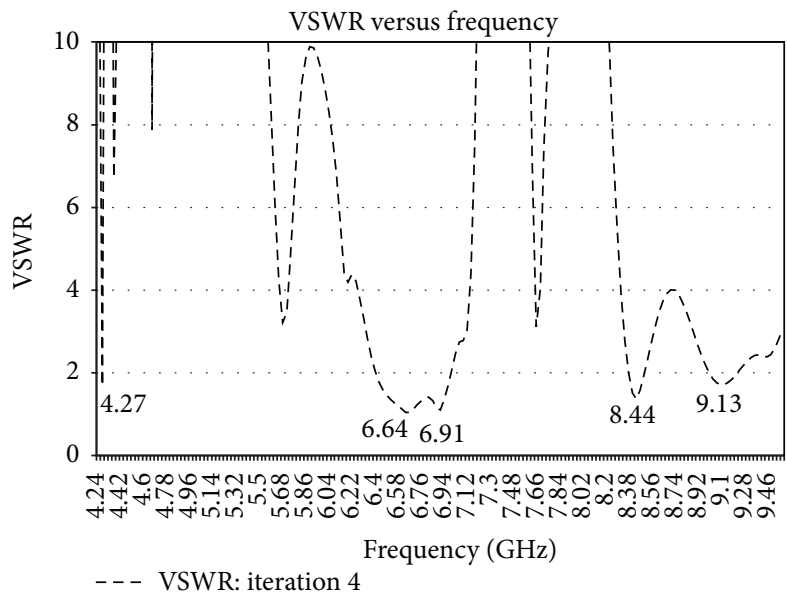

FIGURE 10: VSWR for iteration 4.

reflection coefficient graphs. The VSWR dips below 2 for the corresponding resonating frequency.

As seen in Figures 5, 6, 7, 8, 9, and 10, when an iteration was added to the CRA, the resonating frequencies were

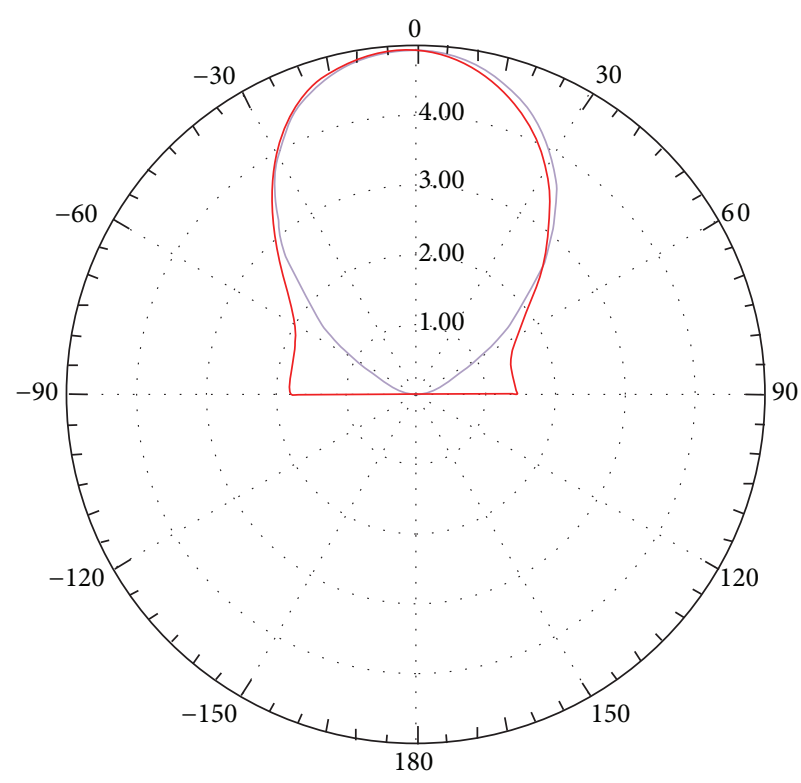

Curve info

$\phi=0 \mathrm{deg}$

- $\phi=90 \mathrm{deg}$

FIGURE 11: Directivity of the CRA for the first iteration at $3.04 \mathrm{GHz}$.

changing. The resonating frequencies for all the iterations are given in Table 1.

The radiation patterns and $3 \mathrm{D}$ and $2 \mathrm{D}$ gains of the CRA were plotted for $3.04 \mathrm{GHz}$ (iteration 1), $6.55 \mathrm{GHz}$ (iteration 2), $8.5 \mathrm{GHz}$ (iteration 3), and $8.44 \mathrm{GHz}$ (iteration 4 ) using HFSS and presented in this paper (Figures 11, 12, 13, 14, 15, 16, 17, 18, $19,20,21$, and 22).

\section{CRA with RF MEMS Switches Results}

The input reflection coefficient $S_{11}$ for the fourth iteration using RF MEMS switches shown in Figure 3 was plotted. This simulations result shown in Figure 22 was obtained using HFSS and is almost the same as the input reflection coefficient 


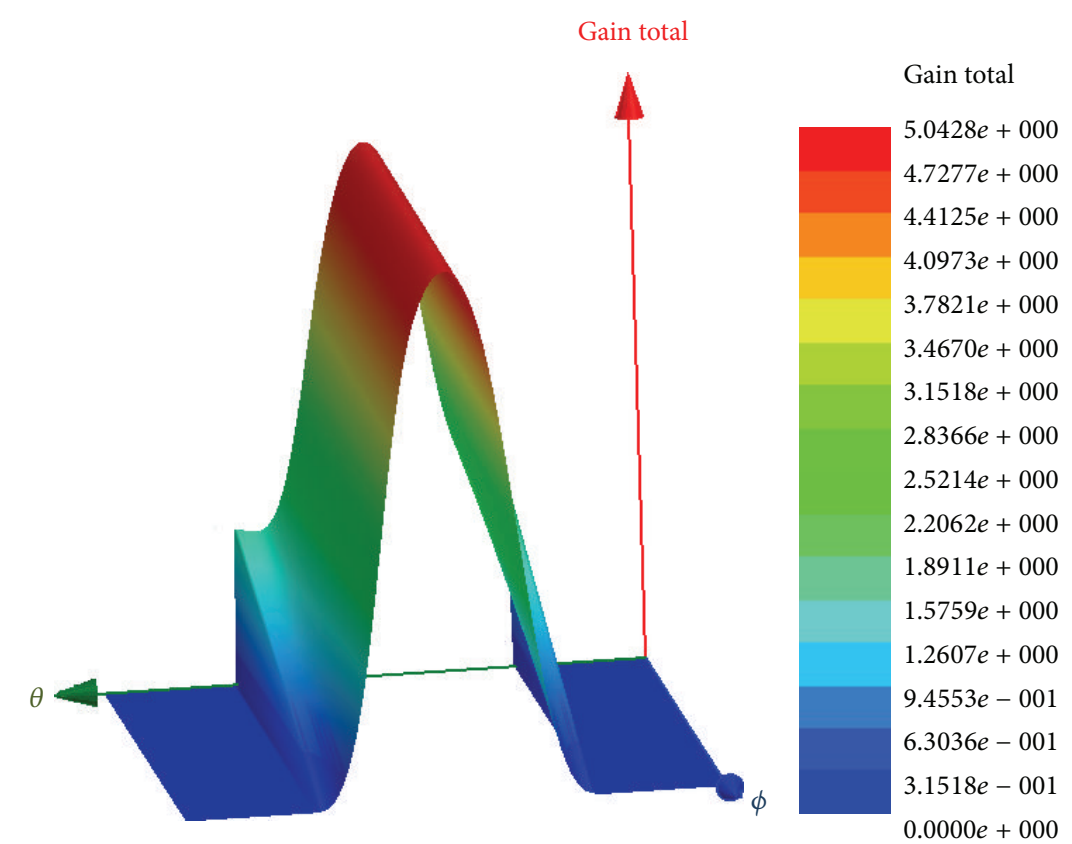

FIGURE 12: 3D gain of the CRA for the first iteration at $3.04 \mathrm{GHz}$.

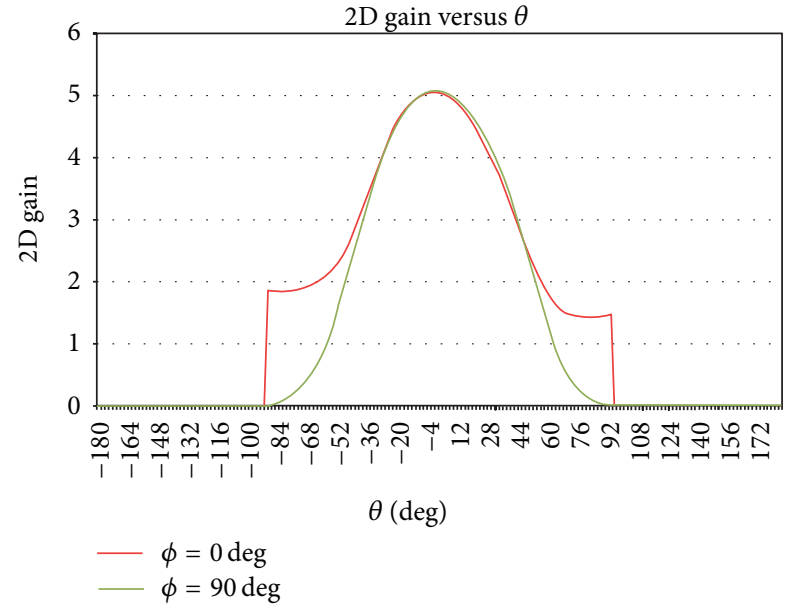

Figure 13: 2D gain of the CRA for the first iteration at $3.04 \mathrm{GHz}$.

TABLE 1: Resonating frequencies of the CRA.

\begin{tabular}{lcc}
\hline Iteration & $\begin{array}{c}\text { Number of resonating } \\
\text { frequencies }\end{array}$ & $\begin{array}{c}\text { Resonating frequencies } \\
(\mathrm{GHz})\end{array}$ \\
\hline 1 & 3 & $3.04,6.4,7.03$ \\
2 & 4 & $6.55,6.85,8.92,9.04$ \\
3 & 5 & $6.58,6.67,6.97,8.5,9.13$ \\
4 & 4 & $4.27,6.64,6.91,8.44,9.13$ \\
\hline
\end{tabular}

$S_{11}$ for the CRA in the fourth iteration from 6 to $10 \mathrm{GHz}$. A resonant frequency of $4.27 \mathrm{GHz}$ is however missing. These results confirm the theory that circuit elements can be used in HFSS to simulate RF MEMS switches $[4,7]$ in the ON state (Figure 23).

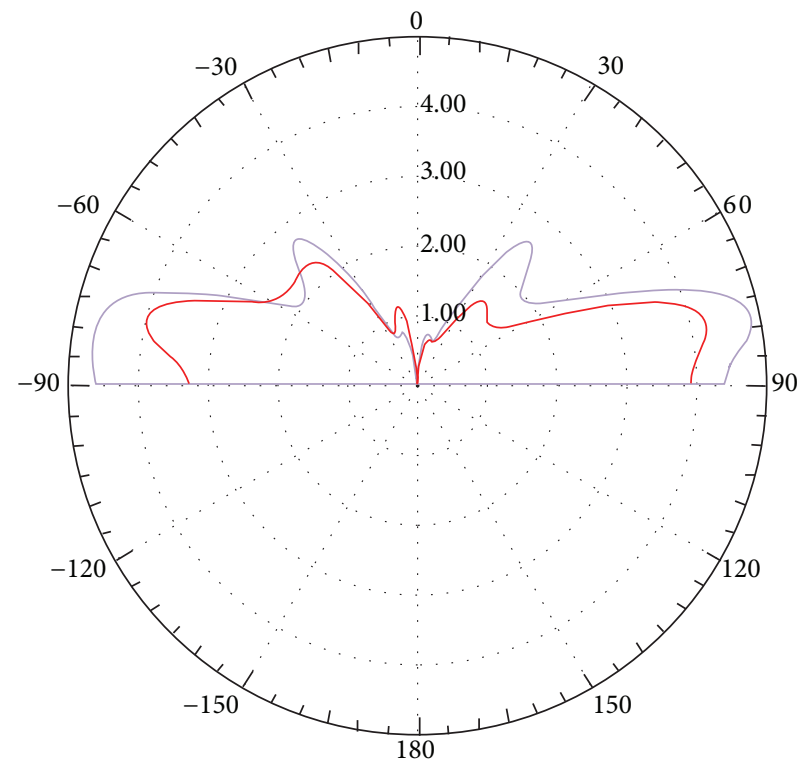

$$
\begin{aligned}
& \text { Curve info } \\
& \begin{aligned}
\phi & =0 \mathrm{deg} \\
\phi & =90 \mathrm{deg}
\end{aligned}
\end{aligned}
$$

FIGURE 14: Directivity of the CRA for the second iteration at $6.55 \mathrm{GHz}$.

\section{Wireless Powering in a Concrete Block}

Three cases were chosen as shown in Table 2. A concrete block of $300 \mathrm{~mm} \times 300 \mathrm{~mm} \times 23 \mathrm{~mm}$ was chosen. The receiver antenna was placed $20 \mathrm{~mm}$ inside the concrete block of $12 \%$ humidity. A transmitting antenna was placed $100 \mathrm{~mm}$ outside 


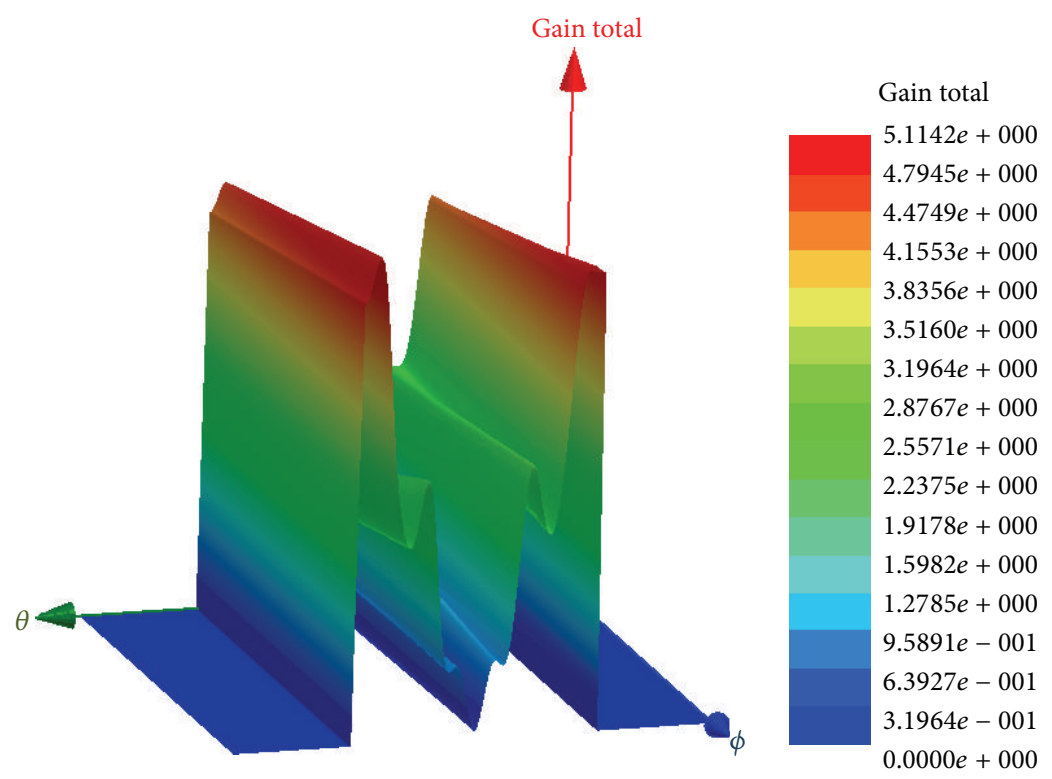

FIgURE 15: 3D gain of the CRA for the second iteration at $6.55 \mathrm{GHz}$.

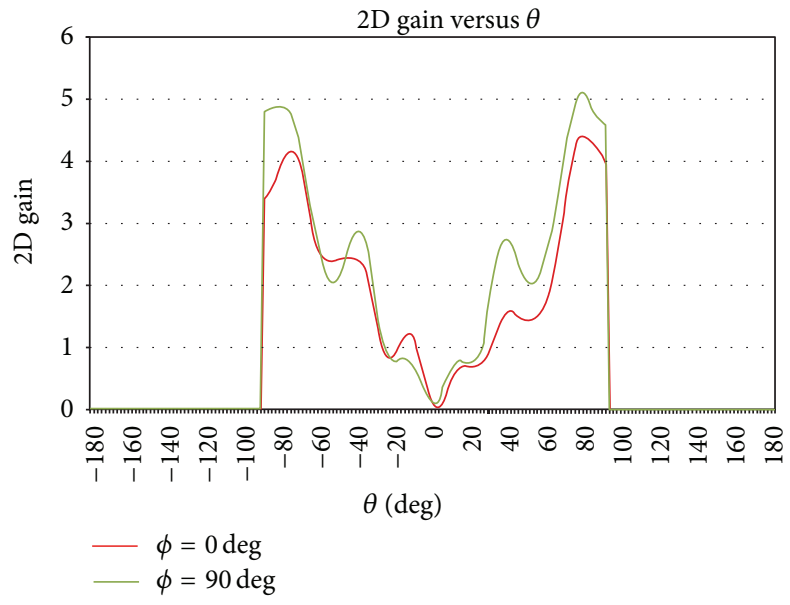

FIGURE 16: 2D gain of the CRA for the second iteration at $6.55 \mathrm{GHz}$.

TABLE 2: The three cases.

\begin{tabular}{lccc}
\hline Case & Frequency $(\mathrm{GHz})$ & Transmitter & Receiver \\
\hline 1 & 0.5 & Dipole & Dipole \\
2 & 0.5 & Dipole & CRA \\
3 & 6.64 & CRA & CRA \\
\hline
\end{tabular}

the concrete block. This arrangement is shown in Figure 24. As stated earlier, the concrete block was simulated in HFSS as a Debye model $[1,5]$. The attenuation of the concrete block is very high at high frequencies $[8,9]$. The dipole used was designed to resonate at a frequency of $500 \mathrm{MHz}$ and the best resonant frequency of $6.64 \mathrm{GHz}$ (iteration 4) shown in Figure 6 was used for the CRA. An input peak current of 10.75798 A was provided to the transmitter using HFSS. The

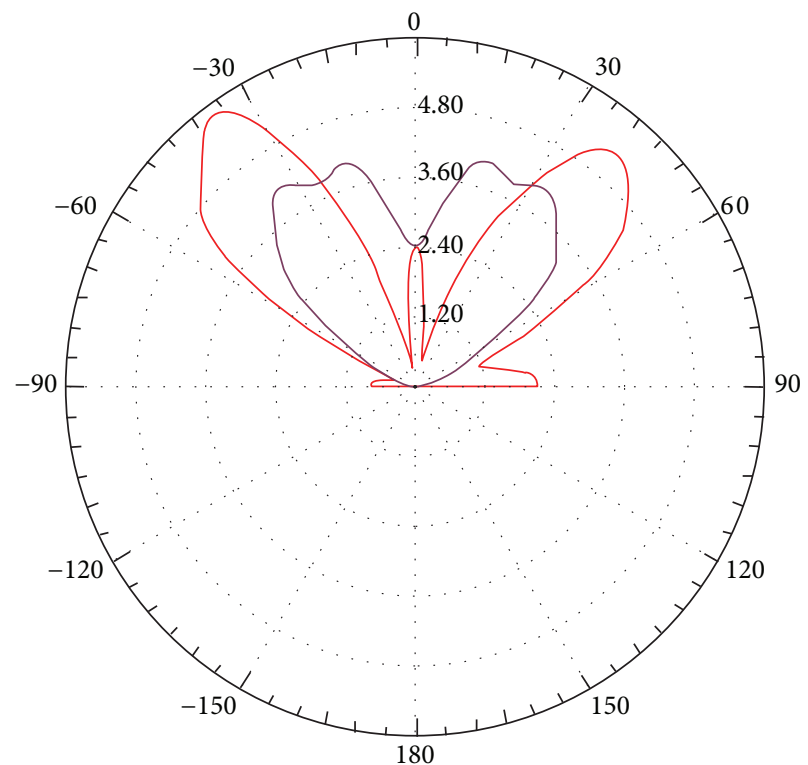

Curve info
$-\phi=0 \mathrm{deg}$
$-\phi=90 \mathrm{deg}$

FIGURE 17: Directivity of the CRA for the third iteration at a frequency of $8.5 \mathrm{GHz}$.

currents measured using HFSS on the surface of the receiver antenna are shown in Table 3.

Even though the CRA in Case 3 is being excited by a very high frequency of $6.64 \mathrm{GHz}$, the received current shown in Table 3 is almost the same as Case 1. The received current was shown to be more than sufficient to power sensors. The use of the CRA antenna is allowing typical wireless sensors 


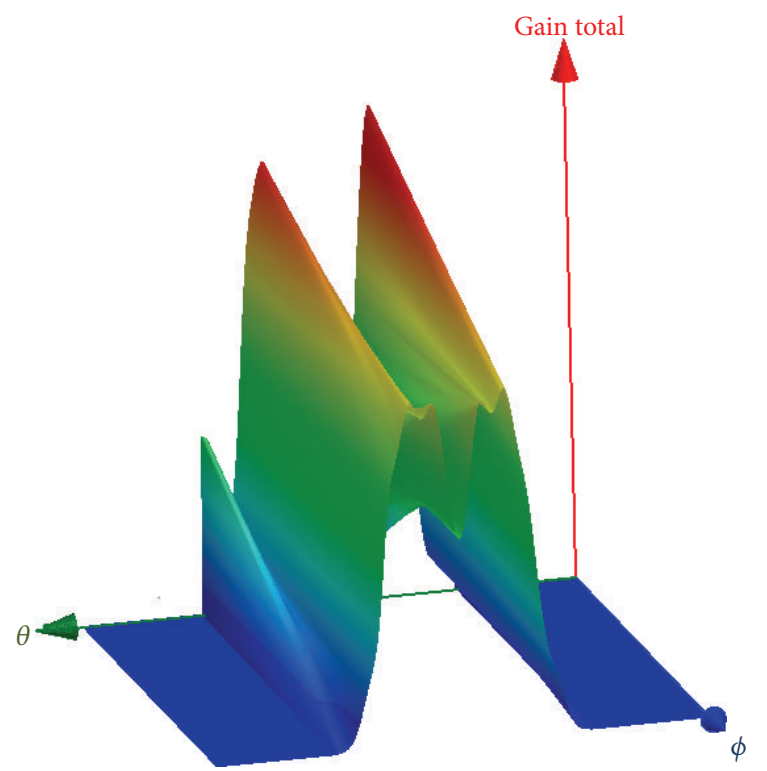

Gain total

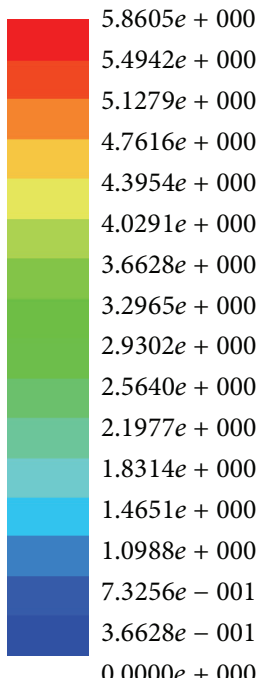

Figure 18: 3D gain of the CRA for the third iteration at $8.5 \mathrm{GHz}$.

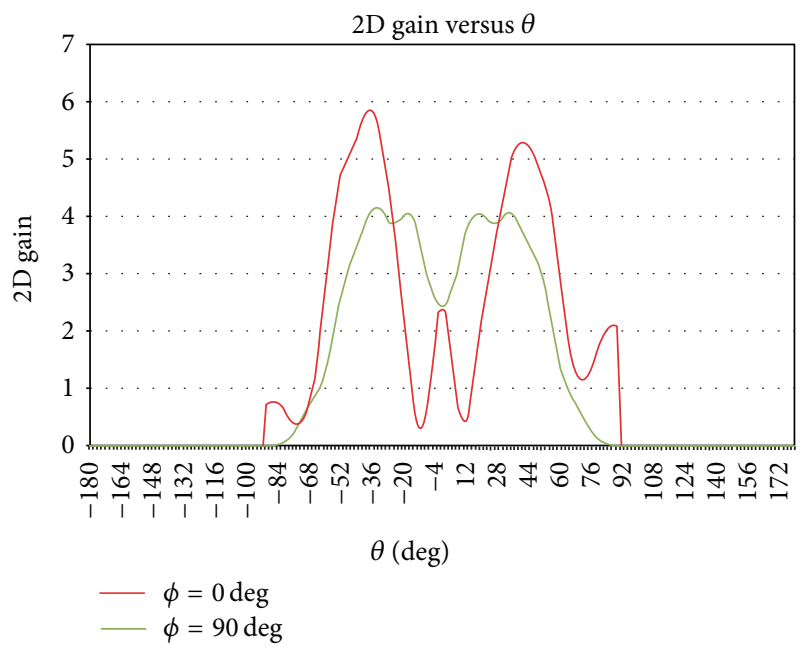

Figure 19: 2D gain of the CRA for the third iteration at $8.5 \mathrm{GHz}$.

TABLE 3: Received currents.

\begin{tabular}{lcc}
\hline Case & Input peak current $(\mathrm{A})$ & Received peak current $(\mathrm{A})$ \\
\hline 1 & 10.75798 & 0.3756 \\
2 & 10.75798 & 0.0238 \\
3 & 10.75798 & 0.3176 \\
\hline
\end{tabular}

shown in Section 5 to be powered at high frequencies which in earlier publication results $[1,9]$ was shown to be very difficult.

\section{Conclusions}

The CRA antenna can be designed for any frequency band. The gain and the radiation pattern of the CRA antenna can be changed by using the switches and changing the iterations.

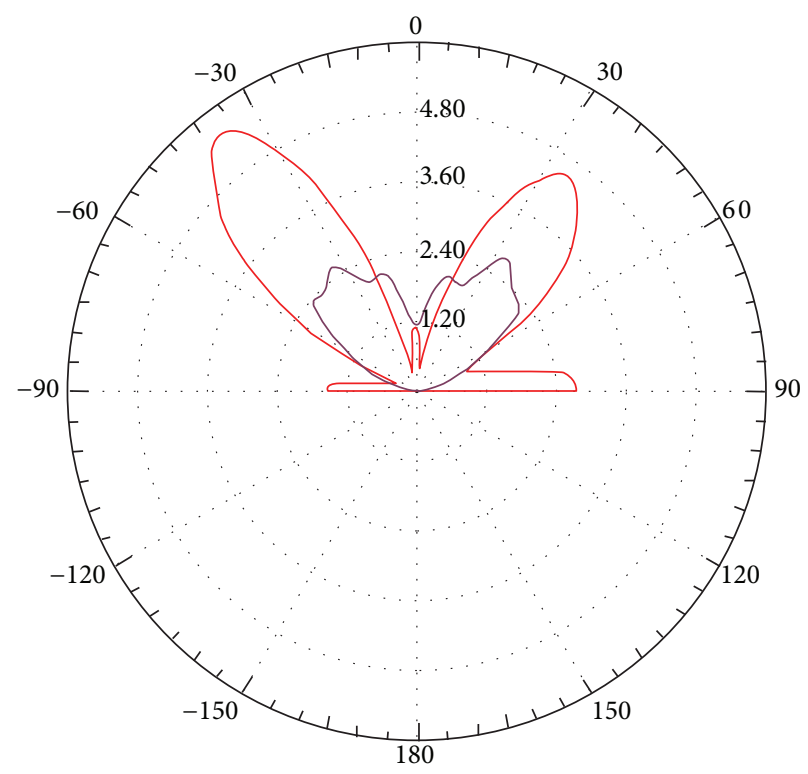

Curve info

$$
\begin{aligned}
\phi & =0 \mathrm{deg} \\
\phi & =90 \mathrm{deg}
\end{aligned}
$$

FIgure 20: Directivity of the CRA for the fourth iteration at $8.44 \mathrm{GHz}$.

The input reflection coefficient $S_{11}$ was shown with RF MEMS switches and the ability of the antenna was verified. The CRA antenna can also be used to power sensors at low as well as high frequencies. The currents received in a concrete slab by the CRA have been presented for the first time in this paper. 


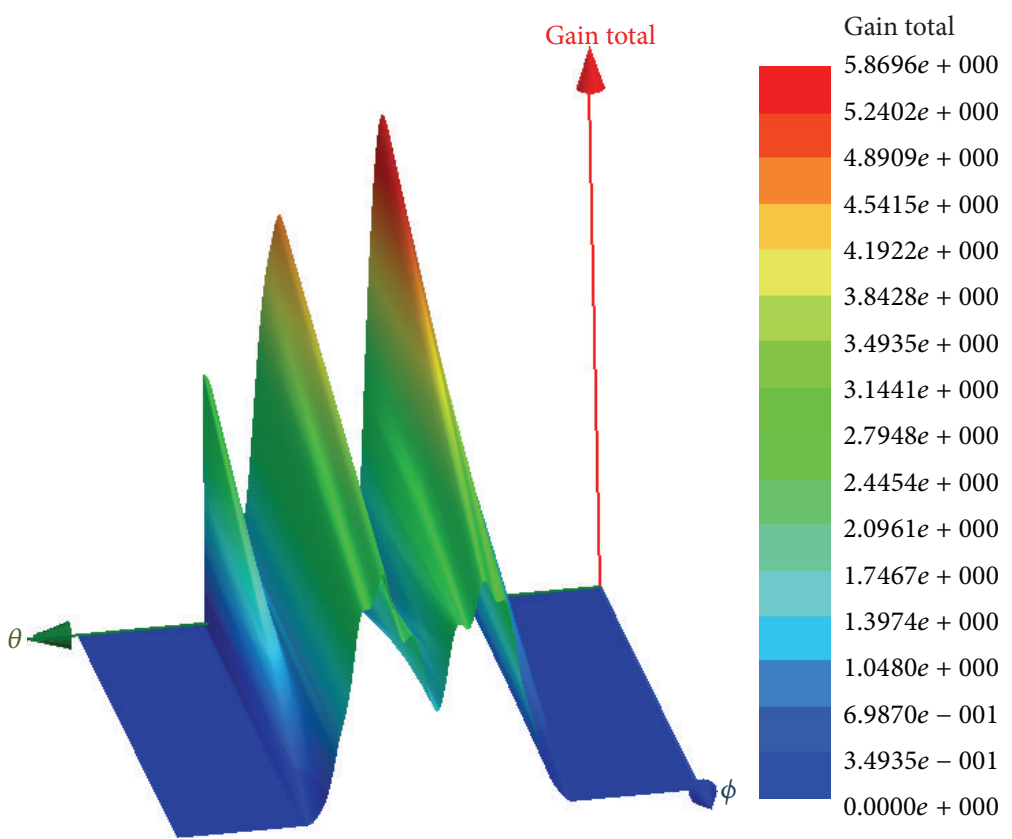

Figure 21: 3D gain of the CRA for the fourth iteration at $8.44 \mathrm{GHz}$.

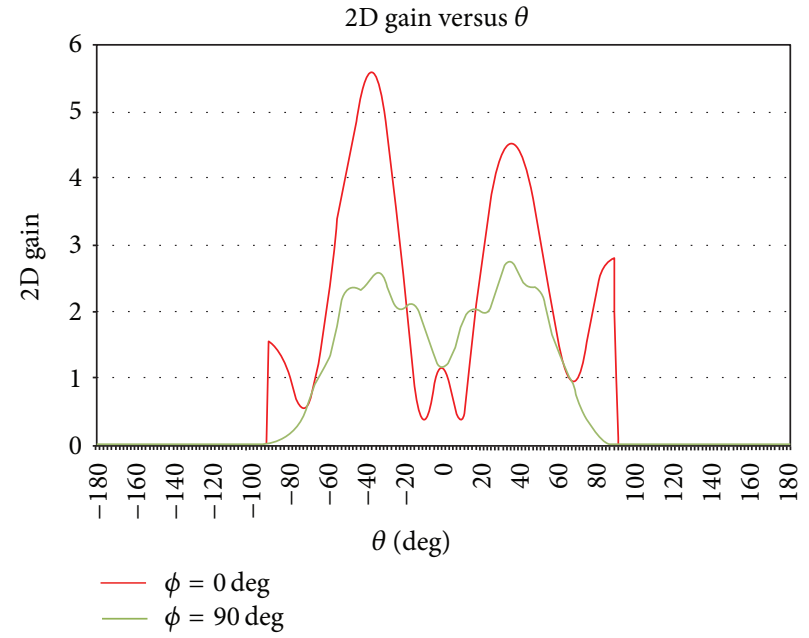

Figure 22: 2D gain of the CRA for the fourth iteration at $8.44 \mathrm{GHz}$.

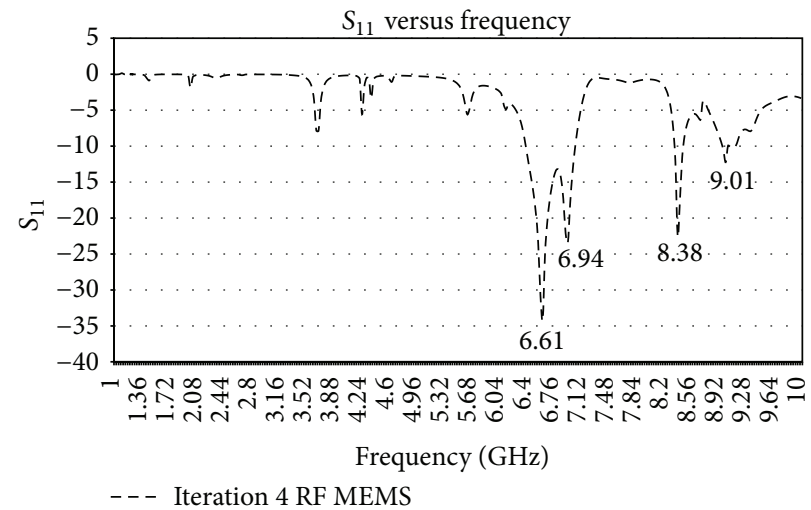

FIgURE 23: $S_{11}$ (RF MEMS switches) versus frequency (GHz). 


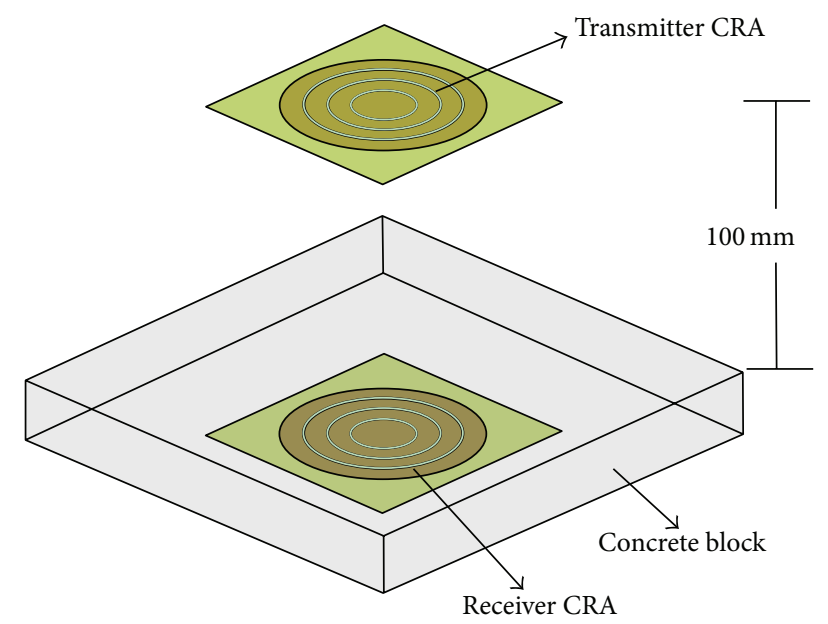

Figure 24: Case 3 layout.

\section{Conflict of Interests}

The authors declare that there is no conflict of interests regarding the publication of this paper.

\section{Acknowledgment}

This work was supported by EIS, Tata Consultancy Services, Pune.

\section{References}

[1] S. S. Punjala, Effective reconfigurable antenna designs to enhance performance and enable wireless powering [FIU Electronic Theses and Dissertations], Florida International University, 2009.

[2] C. Y. Rhee, J. H. Kim, W. J. Jung, T. Park, B. Lee, and C. W. Jung, "Frequency-reconfigurable antenna for broadband airborne applications," IEEE Antennas and Wireless Propagation Letters, vol. 13, pp. 189-192, 2014.

[3] A. Constantine, Antenna Theory Analysis and Design, Wiley, 3rd edition, 2005.

[4] J. Y. Qian, G. P. Li, and F. de Flaviis, "A parametric model of lownoise RF MEMS capacitive switches," in Proceedings of the AsiaPacific Microwave Conference (APMC '01), vol. 3, pp. 1020-1023, December 2001.

[5] L. Sandrolini, U. Reggiani, and A. Ogunsola, "Modelling the electrical properties of concrete for shielding effectiveness prediction," Journal of Physics D: Applied Physics, vol. 40, no. 17, pp. 5366-5372, 2007.

[6] S. A. Bhalerao, A. V. Chaudhary, R. B. Deshmukh, and R. M. Patrikar, "Powering wireless sensor nodes using ambient RF energy," in Proceedings of the IEEE International Conference on Systems, Man and Cybernetics (SMC '06), pp. 2695-2700, IEEE, Taipei, Taiwan, October 2006.

[7] G. H. Huff and J. T. Bernhard, "Integration of packaged RF MEMS switches with radiation pattern reconfigurable square spiral microstrip antennas," IEEE Transactions on Antennas and Propagation, vol. 54, no. 2, pp. 464-469, 2006.

[8] S. S. Punjala and K. Makki, "Wireless powering of sensors in free space and concrete medium," in Proceedings of the 13th International Symposium on Antenna Technology and Applied
Electromagnetics and the Canadian Radio Sciences Meeting (ANTEM/URSI '09), pp. 1-4, February 2009.

[9] S. S. Punjala, "Wireless powering of sensors inside concrete," in Proceedings of the International Conference on Advanced Technologies for Communications (ATC '08), pp. 254-257, October 2008 . 

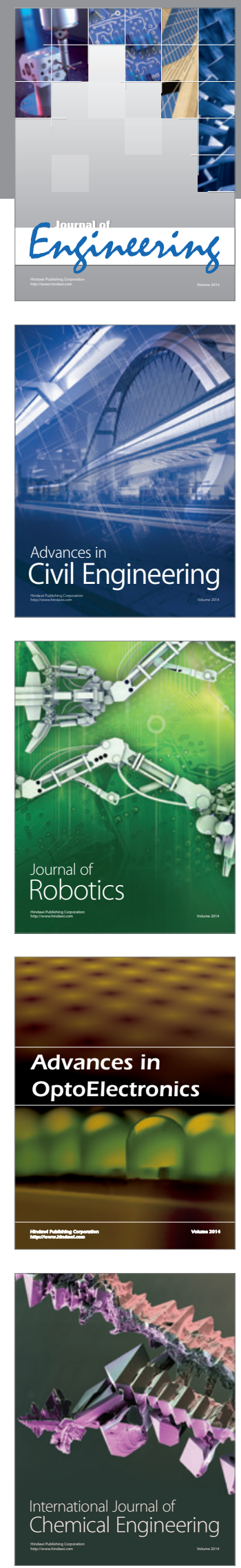

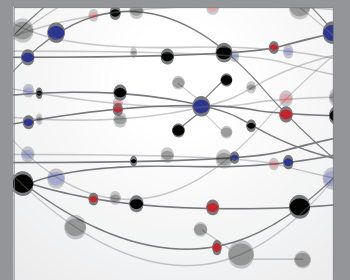

The Scientific World Journal
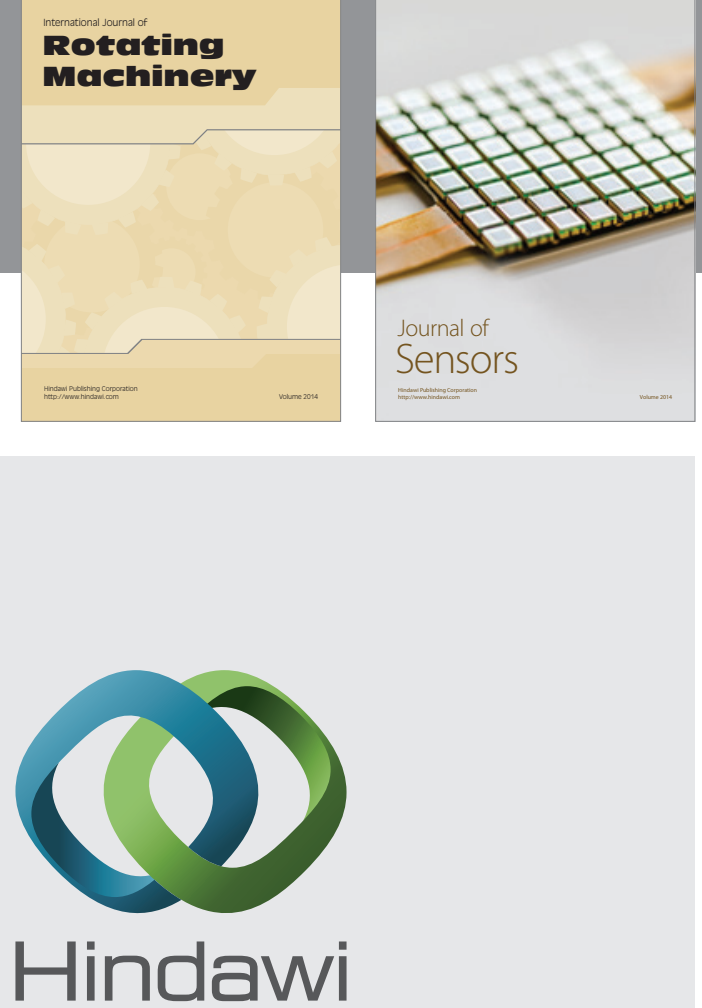

Submit your manuscripts at http://www.hindawi.com
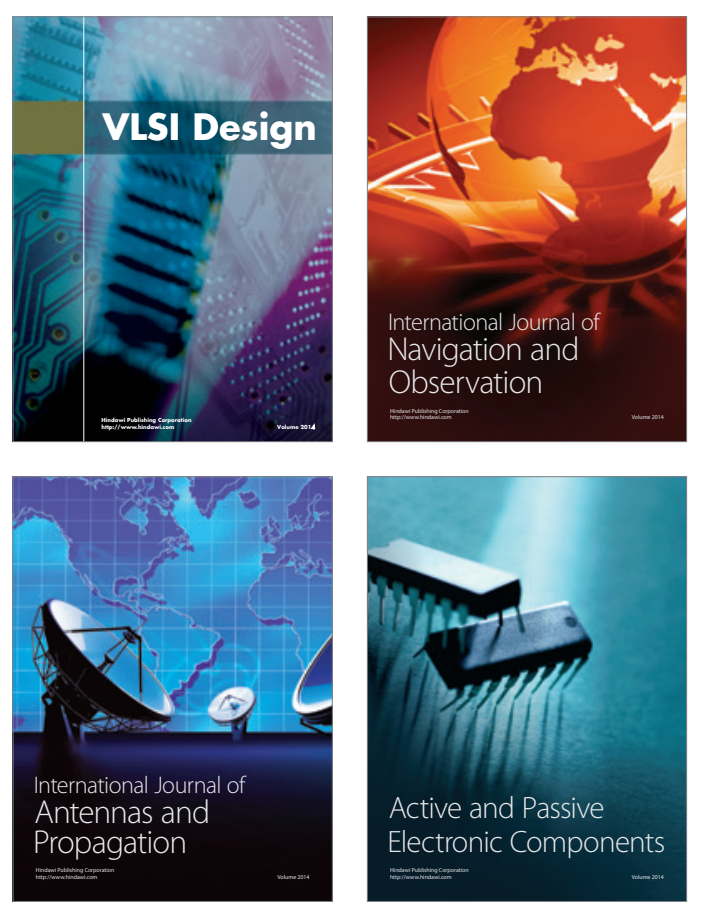
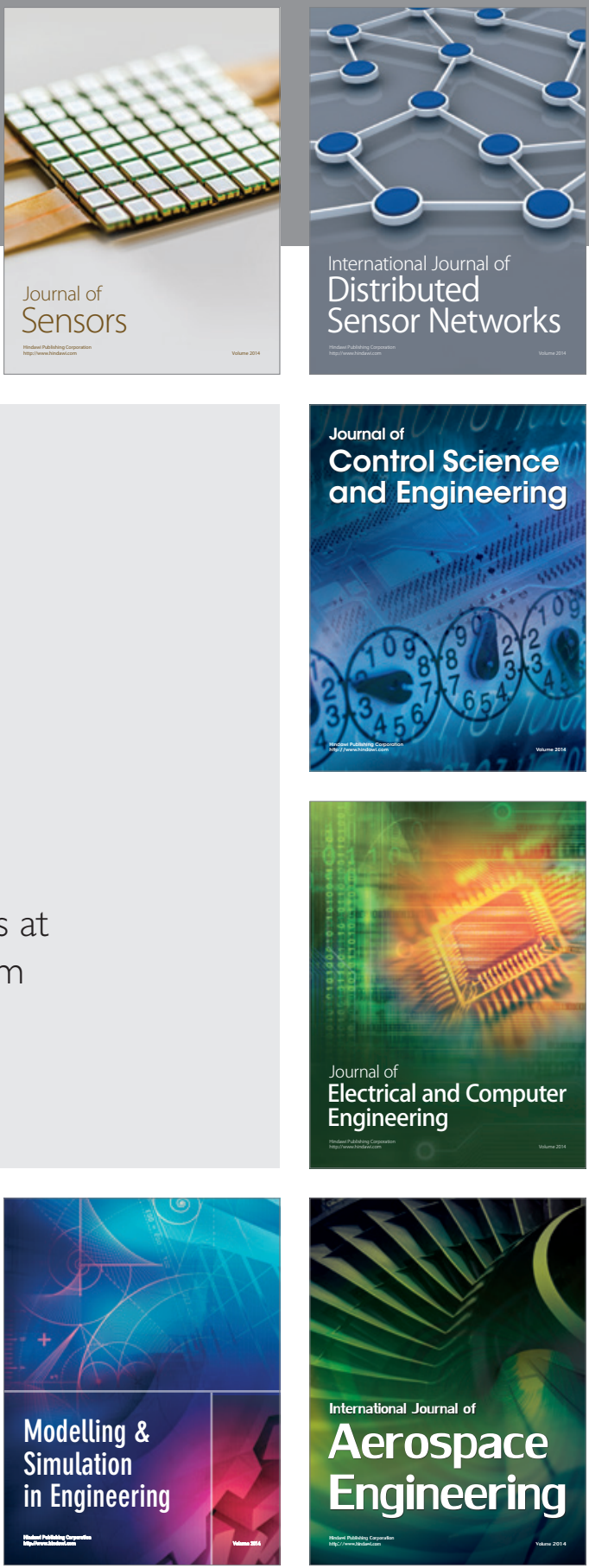

Journal of

Control Science

and Engineering
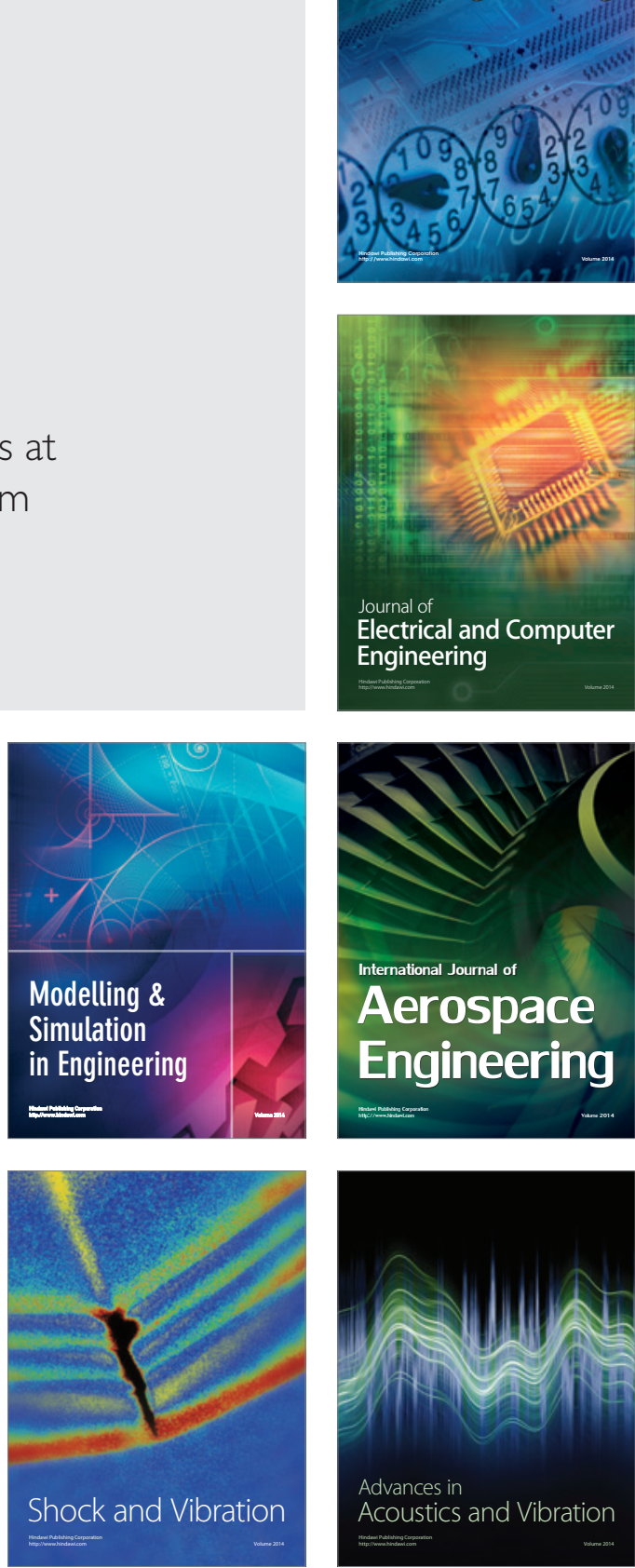